\title{
Penyuluhan Hukum Deteksi Dini Guna Pencegahan Terorisme pada Penghuni Rumah Sewa di Desa Sidomulyo
}

\author{
Rosyida Nurul Anwar', Annisa Putri Noerviana ${ }^{1}$, Meilani Arlindha Putri ${ }^{1}$ \\ ${ }^{I}$ Pendidikan Guru PAUD, Fakultas Keguruan dan Ilmu Pendidikan, Universitas PGRI Madiun, \\ Jl. Setiabudi NO 85,63139 \\ Email Penulis Korespodensi:rosyidanurul@unipma.ac.id
}

\begin{abstract}
The rise of terrorism cases in Indonesia involves terrorists who rent houses or boarding houses. Combating acts of terrorism in Indonesia requires community involvement through various prevention efforts. The purpose of activities is to detect early to prevent acts of terrorism in rental houses by compulsory reporting. The method of implementation is lectures and discussions. The results showed: First, as many as $64 \%$ of the participants stated that the activity was beneficial. Second, in terms of material satisfaction, 93\% of participants were satisfied with the material provided. Third, there is an increase in participants' knowledge about terrorism, its effects, forms, and prevention. The resulting solution is to form a WhatsApp group to get to know each other and socialize. Islam prohibits unrest as part of the practice of jihad. The tendency to grow and develop the ideology of jihad needs to be transformed into a spirit of patriotism and love for the country based on true Islam.
\end{abstract}

\section{Keywords: Early detection, Terrorism, Rental housing}

\begin{abstract}
Abstrak
Maraknya kasus terorisme yang terjadi di Indonesia melibatkan teroris yang menyewa rumah. Pemberantasan aksi terorisme di Indonesia memerlukan keterlibatan masyarakat melalui berbagai upaya pencegahan. Tujuan kegiatan untuk mendeteksi dini guna mencegah terjadinya aksi terorisme di rumah sewa dengan cara wajib lapor. Metode pelaksanaan adalah ceramah dan diskusi. Hasil kegiatan menunjukkan: Pertama, sebanyak 64\% peserta menyatakan kegiatan sangat bermanfaat. Kedua, dari sisi kepuasan materi, 93\% peserta merasa puas dengan materi yang diberikan. Ketiga, terjadi peningkatan pengetahuan peserta mengenai terorisme, efek, bentuk, serta pencegahannya. Solusi yang dihasilkan yaitu membentuk WhatsApp group untuk saling mengenal dan bersosialisasi. Pada dasarnya, Islam melarang sikap menimbulkan keresahan sebagai bagian amalan ibadah jihad. Kecenderungan tumbuh berkembang ideologi jihad perlu bertransformasi menjadi semangat patriotism dan cinta tanah air berdasarkan Islam yang sesungguhnya.
\end{abstract}

\section{Kata kunci: Deteksi dini, Terorisme, Rumah sewa}

\section{PENDAHULUAN}

Indonesia beberapa tahun belakang selalu dikejutkan dengan penangkapan beberapa orang terduga teroris di lingkungan masyarakat. Kebanyakan terduga teroris adalah masyarakat yang tinggal bersama masyarakat dalam sebuah lingkungan yang ramai dan memiliki aktivitas kemasyarakatan yang aktif. Diberitakan melalui Kompas.com bahwa Tim Detasemen Khusus
(Densus) 88 antiteror Polri mengamankan terduga teroris disalah satu tempat rumah sewa atau kost (Kontributor Grobogan, 2020).

Kasus serupa juga terjadi di Bali, sekitar akhir Oktober 2019 terduga teroris berinisial AT ditangkap dan ia merupakan penghuni rumah sewa atau kost dan bekerja sebagai tukang las (Aditya Mardiastuti, 2019). Tahun 2020, di Kota Solo, terjadi aksi penangkapan terduga teroris oleh Densus 88 yang melibatkan terduga teroris 
BE sebagai pemilik indekos dan REP sebagai penghuni kost (Bayu Ardi Isnanto, 2020).

Madiun merupakan kabupaten yang terletak di Provinsi Jawa Timur. Beberapa kasus mengenai terorisme terjadi pada beberapa tahun belakang di Madiun, diantaranya adanya penangkapan pelaku terduga teroris pada Agustus 2019 yang melibatkan satu keluarga. Tim Densus 88 menangkap YN dan istrinya di kawasan Jiwan, Kabupaten Madiun.

Beberapa kasus di atas memberikan sedikit gambaran bahwa maraknya kasus aksi terorisme banyak dilakukan oleh para pelaku yang merupakan penghuni rumah sewa atau indekost. Indekost menjadi sarana para pelaku teroris dalam melancarkan aksinya. Ironisnya para pelaku teroris tersebut adalah orang yang dikenal dan aktif dalam kegiatan kemasyarakatan di sekitar tempat sewanya. Seperti yang diberitakan dibeberapa media bahwa kebanyakan masyarakat lain mengenal para pelaku namun tidak mengenal secara lebih dalam dan tidak menyangka bahwa pelaku terduga teroris yang menjadi tetangga di sekitaran lingkungannya adalah seorang pelaku tindak kriminal. Masyarakat bahkan menilai para pelaku teroris tersebut yang tinggal di rumah sewa atau kost-kostan dipandang sebagai masyarakat yang biasa-biasa saja bahkan berbaur dengan masyarakat sekitar serta aktif dalam kegiatan kemasyarakatan dan keagamaan di lingkungan tersebut.

Pulau Jawa menjadi sarang tumbuh dan berkembangnya pelaku aksi terorisme (Pranowo, 2011, p. 15). Faktanya hampir seluruh teroris yang tertangkap polisi sejak terjadinya tragedy Bom Bali I dan II, bom Marriot, bom Kuningan, bom Poso berasal dari Jawa. Provinsi Jawa Timur yang merupakan bagian dari Pulau Jawa juga tidak lepas dari aksi terorisme. Tahun 2018 terjadi serangan pengeboman di tiga gereja Kota Surabaya yang dilakukan oleh keluarga yang terdiri suami, isteri dan melibatkan anak-anak. Ironis bila kita melihat fenomena dimana keluarga yang melakukan aksi teror melibatkan anak-anak (Anwar, 2021). Anak secara fitrahnya memiliki kebaikan yang ia bawa sejak dalam kandungan, kebaikan-kebaikan yang ia bawa akan berkembang sedan meningkat seiring berjalnnya waktu atas pengasuhan daripada keluarga, lingkungan dan sekolahnya (Anwar et al., 2020). Para pelaku teroris secara tidak langsung merusak fitrah anak dengan menyertakan anak- anak dalam aksi penyerangan dan kekejaman yang ia hadirkan dimata anak.

Aksi terorisme menjadi bentuk dari aksi radikalisme. Radikalisme juga kerap dikaitkan dengan konsep agama yang kemudian sering disebut radikalisme agama sehingga menjadi persoalan yang berhubungan dengan pengalaman inti, memori kolektif dan penafsiran agama (Zuhdi, 2017). Ancaman aksi terorisme tentu sangat berpengaruh terhadap kehidupan dan stabilitas sosial di masyarakat.

Terorisme berasal dari kata terrere (latin) yang berarti rasa takut yang luar biasa (Yunus, 2017). Penyebab utama tindakan terorisme keagamaan adalah ajaran-ajaran agama tertentu yang dianut oleh para pelaku teror. Ajaranajaran agama ini merupakan faktor yang memersiapkan arena bagi terorisme dalam jangka waktu yang panjang. Sedangkan yang menjadi sebab pemicu (trigger causes atau precipitants) terorisme keagamaan adalah kejadian-kejadian khusus yang terjadi sebelum munculnya tindakan terorisme (Naharong, 2014). Teror didefinisikan sebagai usaha menciptakan ketakutan, kengerian, dan kekejaman oleh seseorang atau golongan terentu (Departemen Pendidikan dan Kebudayaan, 2017). Sasaran terorisme dapat berupa masyarakat, pejabat, petugas Negara, dan fasilitas umum.

Penanggulangan aksi terorisme di Indonesia tidak cukup hanya mengandalkan kemampuan aparatur badan Nasonal Penanggulangan Terorisme (BNPT) yang memang diberikan mandat menjalankan amanah tersebut saja, akan tetapi diperlukan seluruh dukungan dari elemen dan tanggungjawab seluruh masyarakat. Partisipasi masyarakat dan lingkungan juga signifikan dalam mengungkap jaringan terorisme. Seperti misalnya, penangkapan jaringan Thorik di Tambora, Jakarta Barat. Penangkapan tersebut tidak lepas dari peran masyarakat untuk berpartisipasi membongkar jaringan terorisme. Selain itu, penangkapan Ridwan alias Ismail Cina yang berasal dari laporan masyarakat (Agus S.B, 2014).

Penegakan hukum memerlukan ketegasan aparat dan kesadaran masyarakat (Kamarullah et al., 2019). Untuk merealisasikan pendekatan kepada berbagai elemen masyarakat, serta memacu partisipasi mereka dalam pencegahan terorisme, BNPT menampung aspirasi, informasi dari masyarakat dengan membentuk Forum Koordinasi Pencegahan Terorisme (FKPT) yang didalamnya melibatkan berbagai 
unsur komunitas masyarakat atau para stakeholders. Hal ini dikarenakan pemerintah (BNPT) mempunyai keterbatasan (Golose, 2009). Keterbatasan yang dimaksud meliputi: sumber dana, sumber daya manusia, dan teknologi (Fahreze, 2020). BNPT yang dikutip oleh Nuraliah Ali, menyatakan bahwa untuk menanggulangi aksi terorisme di masyarakat perlu adanya dorongan dari perangkat desa dan aparatur kelurahan melalui berbagai upaya pencegahan. Mulai dari mengetahui apa itu terorisme, bagaimana pola penyebarannya, bahaya yang ditimbulkan, dan upaya perlakuan tindakan preventif terhadap terorisme (Ali and Fransiska, 2020, pp. 157-163).

Pencegahan terorisme dapat dilakukan dengan memperkuat kekompakan dan solidaritas masyarakat. Pihak kepolisian menganjurkan untuk dengan untuk menggalakkan kembali kegiatan berupa partisipasi wajip lapor di tingkat Rukun Tetangga (RT). Menggalakkan kembali wajib lapor dan memaksimalkan peranan ketua RT, dapat membantu pihak Polri untuk mendeteksi dini keberadaan terorisme. Peranan masyarakat dalam melaporkan gerak-gerik mencurigakan yang terjadi di sekitarnya sangat bermanfaat bagi Polri karena belakangan ini para pelaku teror cenderung tertutup dengan lingkungan sekitarnya.

\section{METODE}

\section{Waktu dan Tempat Pelaksanaan}

Kegiatan pengabdian masyarakat dilaksanakan di rumah kontrakan milik bapak $\mathrm{H}$. Isman, yang berada di kawasan Rukun Tetangga (RT) 024, Rukun Warga (RW) 005, Dusun Sidorejo, Desa Sidomulyo, Kecamatan Sawahan, Kabupaten Madiun, Jawa Timur. Rumah kontrakan tersebut berjumlah 14 rumah dengan penghuni adalah keluarga yang terdiri dari suami, isteri dan anak

\section{Alat dan Bahan: \\ Kegiatan pengabdian kepada masyarakat ini menggunakan alat dan bahan powerpoint, infocus, dan sound system sebagai media persentasi.}

\section{Langkah Pelaksanaan}

Kegiatan pengabdian masyarakat ini melalui beberapa tahapan mulai dari perencanaan, pelaksanaan, dan evaluasi sebagai berikut: Tahapan pertama adalah perencanaan, pada proses ini dimulai dengan survey pada lingkungan masyarakat desa, mengidentifikasi permasalahan yang ada di lingkungan dan menemukan sebuah solusi yang bisa ditawarkan. Tahapan survey juga dengan melihat kondisi rumah sewa dan situasi disekitarnya. Pada proses perencanaan juga dengan melakukan pengurusan izin kegiatan dengan pihak terkait pemerintah tingkat RT dan pengurusan izin kepada pemilik tempat rumah sewa. Proses perencanaan juga dengan melakukan. Tahapan persiapan dilakukan dengan menyiapkan alat, bahan, akomodasi dan transportasi.

Tahapan pelaksanaan kegiatan pengabdian meliputi: Pertama, perkenalan dengan penghuni rumah sewa yang terdiri dari suami, isteri dan anak. Kedua, para penghuni sewa yakni suami dan isteri diminta mengisi kuesioner sebagai pretest sebelum kegiatan penyuluhan dimulai. Ketiga, penyuluhan mengenai materi terorisme yang terdiri dari pengertian terorisme, bagaimana aksi terorisme, bahaya yang ditimbulkan, serta bagaimana partisipasi masyarakat guna mencegahnya menjadi materi pada penyuluhan ini. Materi penyuluhan pentingnya wajib lapor ditingkat RT menjadi materi utama pada penyuluhan ini yang disampaikan kepada peserta untuk memberikan pentingnya wajib lapor ditingkat RT khususnya wilayah perumahan sewa dan terutama jika diketahui ada penyewa baru. Keempat, sesi diskusi, tanya jawab antara peserta dan pengisi materi kegiatan penyuluhan dan dilanjutkan dengan penutup.

Evaluasi menjadi tahapan terakhir pada kegiatan pengabdian, yaitu para peserta kegiatan yakni suami dan isteri penghuni rumah sewa diberikan solusi dalam masyarakat sebagai upaya deteksi dini terorisme.

\section{HASIL DAN PEMBAHASAN}

Pengabdian kepada masyarakat ini diikuti oleh seluruh keluarga pada rumah sewa yang terdiri dari suami dan isteri berjumlah 14 Kartu Keluarga (KK) dengan total 28 peserta. Peserta kegiatan yang merupakan penghuni rumah sewa berasal dari berbagai daerah dengan latar belakang pekerjaan dan pendidikan yang berbeda-beda.

Tabel 1. Data Personal Peserta

\begin{tabular}{lllll}
\hline KK & Nama & Usia & Pendidikan & Pekerjaan \\
\hline 1. & SG & 73 & SMA & Wiraswasta \\
\hline
\end{tabular}




\begin{tabular}{|c|c|c|c|c|}
\hline KK & Nama & Usia & Pendidikan & Pekerjaan \\
\hline & $\mathrm{SD}$ & 66 & SMP & $\begin{array}{l}\text { Ibu Rumah } \\
\text { Tangga }\end{array}$ \\
\hline \multirow[t]{2}{*}{2.} & MS & 34 & SMP & Wiraswasta \\
\hline & WA & 21 & SMA & $\begin{array}{l}\text { Ibu Rumah } \\
\text { Tangga }\end{array}$ \\
\hline \multirow[t]{2}{*}{3.} & DY & 30 & S1 & $\begin{array}{l}\text { Karyawan } \\
\text { Swasta }\end{array}$ \\
\hline & $\mathrm{CP}$ & 25 & S1 & Wiraswasta \\
\hline \multirow[t]{2}{*}{4.} & SY & 37 & SMA & $\begin{array}{l}\text { Karyawan } \\
\text { Swasta }\end{array}$ \\
\hline & MD & 31 & SMA & $\begin{array}{l}\text { Karyawan } \\
\text { Swasta }\end{array}$ \\
\hline \multirow[t]{2}{*}{5.} & AS & 32 & SMA & $\begin{array}{l}\text { Karyawan } \\
\text { Swasta }\end{array}$ \\
\hline & SN & 40 & SD & $\begin{array}{l}\text { Ibu Rumah } \\
\text { Tangga }\end{array}$ \\
\hline \multirow[t]{2}{*}{6.} & ES & 39 & SMA & $\begin{array}{l}\text { Karyawan } \\
\text { Swasta }\end{array}$ \\
\hline & JS & 51 & D3 & $\begin{array}{l}\text { Karyawan } \\
\text { Swasta }\end{array}$ \\
\hline \multirow[t]{2}{*}{7.} & KT & 36 & SMA & $\begin{array}{l}\text { Karyawan } \\
\text { Swasta }\end{array}$ \\
\hline & EW & 32 & SMA & $\begin{array}{l}\text { Karyawan } \\
\text { Swasta }\end{array}$ \\
\hline \multirow[t]{2}{*}{8.} & FT & 32 & SMA & Wiraswasta \\
\hline & RA & 29 & S1 & $\begin{array}{l}\text { Karyawan } \\
\text { Swasta }\end{array}$ \\
\hline \multirow[t]{2}{*}{9.} & IR & 40 & SMA & Wiraswasta \\
\hline & WT & 28 & SMA & $\begin{array}{l}\text { Ibu Rumah } \\
\text { Tangga }\end{array}$ \\
\hline \multirow[t]{2}{*}{10.} & AW & 36 & SMA & $\begin{array}{l}\text { Karyawan } \\
\text { Swasta }\end{array}$ \\
\hline & $\mathrm{TH}$ & 38 & SMA & $\begin{array}{l}\text { Ibu Rumah } \\
\text { Tangga }\end{array}$ \\
\hline \multirow[t]{2}{*}{11.} & RS & 29 & SMA & $\begin{array}{l}\text { Karyawan } \\
\text { Swasta }\end{array}$ \\
\hline & RR & 28 & SD & $\begin{array}{l}\text { Ibu Rumah } \\
\text { Tangga }\end{array}$ \\
\hline \multirow[t]{2}{*}{12.} & SS & 31 & SMA & Wiraswasta \\
\hline & SR & 24 & SMA & $\begin{array}{l}\text { Ibu Rumah } \\
\text { Tangga }\end{array}$ \\
\hline \multirow[t]{2}{*}{13.} & HW & 36 & SMA & Wiraswasta \\
\hline & TW & 26 & SMA & Wiraswasta \\
\hline \multirow[t]{2}{*}{14.} & SY & 28 & SMA & $\begin{array}{l}\text { Karyawan } \\
\text { Swasta }\end{array}$ \\
\hline & TW & 27 & SMA & $\begin{array}{l}\text { Karyawan } \\
\text { Swasta }\end{array}$ \\
\hline
\end{tabular}

Berdasarkan Tabel 1, didapatkan bahwa para penghuni rumah sewa memiliki latar belakang pendidikan hingga wajib belajar 9 tahun saja atau setara dengan SMA, hal ini disebabkan kurangnya biaya untuk dapat melanjutkan pendidikan ke jenjang yang lebih tinggi. Para penghuni rumah sewa kebanyakan adalah karyawan swasta yang bekerja di sekitaran Maresidenan Madiun. Usaha para penghuni rumah sewa yang wiraswasta adalah berdagang.

Kegiatan penyuluhan diawali dengan memberikan pertanyaan awal (pretest) kepada para penghuni rumah sewa berupa pertanyaan seputaran lingkungan masyarakat dan terorisme yang terjadi di Indonesia, pada pretest hanya terdapat dua soal dengan tujuan mengetahui seberapa besar tingkat pengenalan penghuni rumah sewa dan pengenalan terorisme, yaitu: Pertama, mengenai tingkat saling mengenal oleh para penghuni rumah sewa, hasil menunjukkan bahwa sebagian besar $71 \%$ para penghuni rumah sewa saling tidak mengenal.

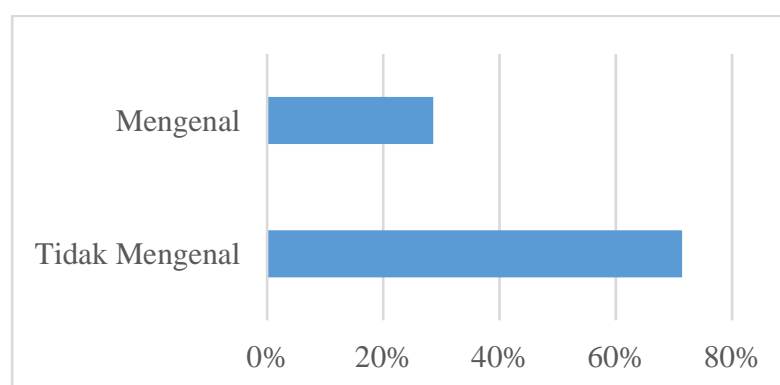

Gambar 1. Tingkat Pengenalan Penghuni Rumah Sewa

Berdasarkan Gambar 1, sebanyak 20 orang (71\%) tidak saling mengenal antar penghuni rumah sewa maupun masyarakat di lingkungan RT maupun dusun. Hal ini disebabkan oleh kesibukan masing-masing individu ketika yaitu bekerja, sehingga kurangnya intensitas saling bertemu. Selain itu para penghuni rumah sewa kebanyakan juga tidak ikut serta dalam beberapa kegiatan kemayarakatan seperti majelis taklim, posyandu, kerja bakti, jaga pos ronda, arisan RT sehingga mengakibatkan kurangnya berinteraksi dengan masyarakat setempat.

Berdasarkan kendala-kendala tersebut, maka sebagai bagian dari hukum deteksi dini upaya pencegahan terorisme, maka dibentuklah sebuah komunitas berupa grup whatsApp (WAG) oleh para penghuni rumah sewa serta pemilik asli rumah sewa, agar dapat saling mengenal dan bersosialisasi.

Kedua, pengetahuan peserta mengenai keberadaan kelompok yang menggunakan caracara kekerasan dan teror menunjukkan hasil bahwa peserta sebagian besar $86 \%$ tidak mengetahui maupun mendengar keberadaan kelompok-kelompok terorisme. 


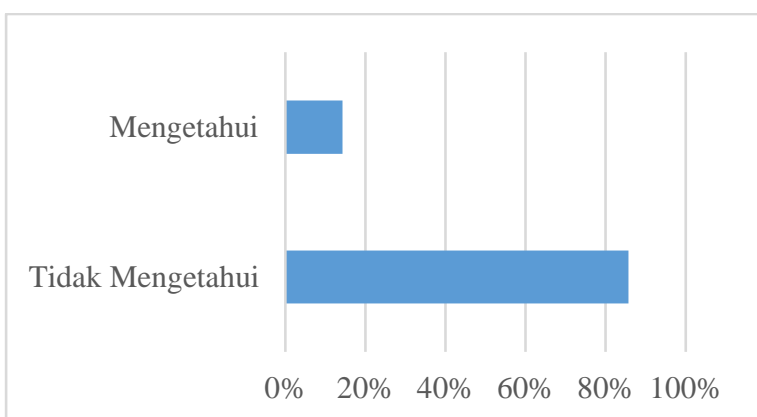

Gambar 2. Tingkat Pengetahuan Kelompok Terorisme

Hasil diagram diatas, sebanyak 24 penghuni rumah sewa tidak mengetahui keberadaan kelompok teririsme yang ada di Indonesia. Hal ini dikarenakan kurangnya pengetahuan dan perhatian mengenai isu-isu terorisme yang ada di Indonesia oleh para penghuni sewa. Hal tersebut terjadi disebabkan waktu yang digunakan para penghuni rumah sewa digunakan untuk bekerja, mencari nafkah untuk membiayai keluarga.

Pelaksanaan penyampaian materi penyuluhan pada kegiatan pengabdian pada masyarakat dilakukan dengan pemberian pengetahuan mengenai hukum deteksi dini pencegahan terorisme dengan melakukan wajib lapor oleh Ketua RT. Wajib lapor sebagai upaya ketua RT sebagai pemimpin mengetahui warga yang ada di lingkungannya. Wajib lapor dengan memberikan fotokopi identitas diri dan KK. Wajib lapor yang dilakukan oleh penghuni rumah sewa juga bermanfaat sebagai data dasar di pedesaan, sehingga dapat dimanfaatkan demi kepentingan bersama.

Penyuluhan dilakukan juga dengan pemberian materi mengenai seputaran terorisme dan upaya pencegahannya, serta dampak yang ditimbulkan. Pada dasarnya Islam tidak mengajarkan sikap kekerasan, teror yang menimbulkan keresahan sebagai bagian dari amalan ibadah dan jihad (Anwar and Muhayati, 2021). Kecenderungan tumbuh dan berkembangan ideologi jihadis, perlu ditransformasikan ke dalam semangat patriotism, cinta tanah air, memiliki landasan nash al Qur'an dan sunnah yang kuat (Mufid, 2013).

Kebermanfaat penyuluhan sebagai bagian dari evaluasi kegiatan dirasakan oleh para peserta sebanyak $64 \%$ menyatakan sangat bermanfaat, 29\% cukup bermanfaat. Dengan demikian materi yang disajikan pada penyuluhan dirasakan manfaatnya oleh sebagian besar para peserta yang merupakan para penghuni rumah sewa.

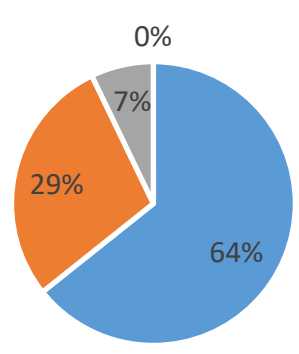

Gambar 3. Tingkat Kebermanfaatan Materi

Ditinjau dari aspek kompetensi pemateri/fasilitator meliputi penguasaan materi, sistematika penyajian materi, penggunaan metode secara umum sebanayak 100\% peserta menilai baik.

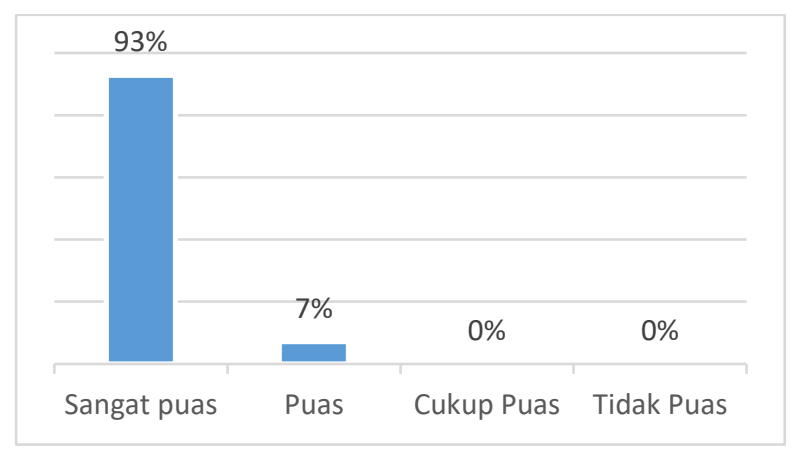

Gambar 4. Tingkat Kepuasan Pemateri

Hal tersebut di atas menunjukkan bahwa peserta puas dengan pemateri yang dihadirkan pada kegiatan penyuluhan. Secara umum terjadi peningkatan pemahaman dan pengetahuan peserta mengenai seputaran hukum deteksi dini dan upaya pencegahan terorisme.

\section{SIMPULAN DAN SARAN}

Kegiatan pengabdian kepada masyarakat berupa penyuluhan hukum deteksi dini guna pencegahan terorisme pada penghuni rumah sewa milik bapak $\mathrm{H}$. Isman, yang berada di kawasan RT 024, Rukun Warga (RW) 005, Dusun Sidorejo, Desa Sidomulyo, Kecamatan Sawahan, Kabupaten Madiun, Jawa Timur terlaksana dengan baik. Pelaksanaan penyuluhan dengan memberikan pemahaman mengenai pentingnya wajib lapor sebagai bagian dari deteksi dini terorisme di lingkungan. Penguatan upaya pencegahan aksi terorisme 
dilakukan dengan memberikan pengetahuan mengenai seputaran terorisme, dampak yang ditimbulkan serta upaya pencegahan yang bisa dilkukan oleh para peserta. Upaya penyelesaian terhadap kendala yang dirasakan oleh para penghuni rumah sewa sebagai upaya deteksi dini aksi terorisme dengan membentuk grup whatsApp (WAG) oleh para penghuni rumah sewa serta pemilik asli rumah sewa, agar dapat saling mengenal dan bersosialisasi.

Saran yang diberikan yakni melakukan kegiatan penyuluhan, pembinaan, pelatihan dengan tema serupa di kawasan-kawasan kost, rumah sewa, wisma, homestay dan sejenisnya dilokasi berbeda agar dapat memaksimalkan pencegahan terorisme di Indonesia. Keberlanjutan pada kegiatan ini adalah dengan memberikan penyuluhan dan pencegahan penanggulangan terorisme pada masyarakat sejak dini seperti memberikan nilai-nilai komitmen kebangsaan pada penghuni dan penguatan nilai moderat.

\section{DAFTAR PUSTAKA}

Aditya Mardiastuti (2019) 'Terduga Teroris Bali Kos di Denpasar dan Kerja sebagai Tukang Las', Detik News. Available at: Detik.com.

Agus S.B (2014) Merintis Jalan Mencegah Terorisme (Sebuah Bunga Rampai). Jakarta: Semarak Lautan warna.

Ali, N. and Fransiska, P. (2020) Abdimas Lintas Kampus Untuk Indonesia: Bidang Ekonomi Bisnis, Pendidikan, Agama, Sosial, Lingkungan, Kesehatan, Hukum, Manajemen, Sains dan teknologi. Yogyakarta: Samudera Biru.

Anwar, R. N. et al. (2020) 'Penguatan Orangtua Di Tengah Pandemi Guna Dalam Menjaga Fitrah Anak', in E-Prosiding Hapemas. Malang: Universitas Negeri Malang, pp. 386-392.

Anwar, R. N. (2021) 'Penanaman Nilai-Nilai Islam Moderat Pada Anak Usia Dini Dalam Keluarga Sebagai Upaya Menangkal Radikalisme', Al Fitrah Journal Of Early Childhood Islamic Education, 4(2), pp. 155163.
Anwar, R. N. and Muhayati, S. (2021) 'Upaya Membangun Sikap Moderasi Beragama Melalui Pendidikan Agama Islam Pada Mahasiswa Perguruan Tinggi Umum', AlTadzkiyyah: Jurnal Pendidikan Islam, 12(1), pp. 1-15.

Bayu Ardi Isnanto (2020) 'Densus Juga Tangkap Satu Warga Pemilik Indekos di Solo', Detik News. Available at: Detik.com.

Departemen Pendidikan dan Kebudayaan (2017) Kamus Besar Bahasa Indonesia. V. Jakarta: Balai Pustaka.

Fahreze, A. (2020) 'Pencegahan Terorisme Berbasis Masyarakat Dengan Pembentukan Forum Koordinasi Pencegahan Terorisme Di Tiga Provinsi', Jurnal Sosiologi Nusantara, 6(1), pp. 13-22.

Golose, P. R. (2009) Deradikalisasi Terorisme: Humanis, Soul Approach dan Menyentuh Akar Rumput. Yayasan Pengembangan Kajian Ilmu Kepolisian.

Kamarullah et al. (2019) 'Peningkatan Perilaku Peduli Hukum Dan Lingkungan Melalui Program Kemitraan Masyarakat Peduli Hukum', Dinamisia: Jurnal Pengabdian Kepada Masyarakat, 3(1), pp. 1-6.

Kontributor Grobogan, P. D. P. N. (2020) 'Densus 88 Tangkap 3 Orang dari Kamar Kos di Jepara', Kompas.com. Available at: Kompas.com.

Mufid, A. S. (2013) 'Radikalisme dan Terorisme Agama, Sebab dan Upaya Pencegahannya', Jurna; Multikulturan \& Multireligius, 12(1), pp. 7-17.

Naharong, A. M. (2014) 'Terorisme atas Nama Agama', Refleksi, 13(5), pp. 593-622. doi: 10.15408/ref.v13i5.915.

Pranowo, M. B. (2011) Orang Jawa Jadi Teroris. Jakarta: Pustaka Alvabet.

Yunus, A. F. (2017) 'Radikalisme, Liberalisme dan Terorisme: Pengaruhnya Terhadap Agama Islam', Jurnal Online Studi Al-Qur an, 13(1), pp. 76-94. doi: 10.21009/jsq.013.1.06.

Zuhdi, M. H. (2017) 'Radikalisme Agama dan Upaya Deradikalisasi Pemahaman Keagamaan', Akademika, 22(11), pp. 199224. 